\title{
AACP REPORT
}

\section{AACP Special Taskforce on Diversifying Our Investment in Human Capital Interim Update}

\author{
Carla White, ${ }^{a^{*}}$ Jennifer Adams ${ }^{\mathrm{b}}$ \\ ${ }^{a}$ Eshelman School of Pharmacy, University of North Carolina at Chapel Hill, Chapel Hill, North Carolina \\ ${ }^{\mathrm{b}}$ American Association of Colleges of Pharmacy, Alexandria, Virginia \\ * Chair
}

\section{EXECUTIVE SUMMARY}

The 2015-2017 AACP Special Taskforce on Diversifying our Investment in Human Capital was appointed for a two-year term, therefore the interim update from the Taskforce. A full report will be provided in 2017 in the form of a white paper for academic pharmacy on diversifying our investment in human capital.

Keywords: diversity, health equity, human capital, standing committee

\section{INTRODUCTION AND COMMITTEE CHARGES}

The 2013-14 Argus Commission assessed the status of academic pharmacy with respect to diversity and inclusion in the broadest sense of these terms and in all elements of the academic mission. Two policy statements were forwarded for adoption by the House of Delegates and seven recommendations were made for a significantly expanded effort in support of our members' goals in this area. The 2014-15 Strategic Planning Committee discussed this area as needing "a game-changer." In order to address these recommendations and to further assess the successful practices of members and colleague organizations, the Special Taskforce on Diversifying Our Investment in Human Capital will be appointed for the period 2015-17 to:

1. Identify barriers to accelerating diversification of the people who comprise our human capital in colleges/schools of pharmacy.

2. Identify game-changers in professional education, health care, or related areas in which substantial improvements in human capital diversification have been achieved.

3. Examine and recommend short-term and longterm strategies (e.g., changes to the application information collected, a national research agenda). The Taskforce is asked to vet strategies through the AACP Councils for input, with consideration to existing diversity plans at member institutions, and through external stakeholder organizations. The taskforce members are:

- Carla Y. White, BS, Chair (Assistant Dean, University of North Carolina at Chapel Hill)

- Jeannine M. Conway, PharmD (Assistant Dean, University of Minnesota)
- Paula K. Davis, MA (Assistant Vice Chancellor, University of Pittsburgh)

- Arcelia M. Johnson-Frannin, PharmD, PhD (Dean, University of the Incarnate Word)

- Jeffry G. Jurkas, BS (Coordinator of Admissions and Recruitment, Nova Southeastern University)

- Nanci L. Murphy, PharmD (Associate Dean, University of Washington)

- W. Thomas Smith, PharmD, JD (Clinical Associate Professor, Manchester University)

- Margarita Echeverri, PhD (Assistant Professor and Educational Coordinator, Xavier University of Louisiana)

- Sharon L. Youmans, PharmD (Professor of Clinical Pharmacy, University of California, San Francisco)

- Jennifer Adams (Senior Advisor of Student Affairs, AACP)

\section{BACKGROUND}

The 2013-2014 Argus Commission presented some analyses of under-representation in pharmacy in their report based on the U.S. Census:

"When compared with the 2010 US Census, population demographics, pharmacy school applications and enrollments in 2012, respectively, have underrepresentation among Whites (-36.1\%/-19.2\%), Blacks/African Americans (-2.4\%/-5.7\%), Hispanics or Latinos (-11.1\%/-12.3\%), and American Indians or Alaska Natives $(-0.7 \% /-0.5 \%)$, while Asians are overrepresented $(+29.4 \% /+18.8 \%)$ and Native Hawaiian or other Pacific islanders have $0.8 \%$ over-representation among those admitted, while their application percentages equate to the 2010 population demographics." (Read More: http://www.ajpe.org/doi/full/10.5688/ ajpe7810S21) 


\section{American Journal of Pharmaceutical Education 2016; 80 (7) Article S6.}

The taskforce considered this information along with definitions of under-representation in medicine:

On March 19, 2004, the AAMC Executive Committee adopted a clarification to its definition of "underrepresented in medicine" following the Supreme Court's decision in Grutter.

The AAMC definition of underrepresented in medicine is: "Underrepresented in medicine means those racial and ethnic populations that are underrepresented in the medical profession relative to their numbers in the general population."

Adopted by the AAMC's Executive Council on June 26, 2003, the definition helps medical schools accomplish three important objectives:

- a shift in focus from a fixed aggregation of four racial and ethnic groups to a continually evolving underlying reality. The definition accommodates including and removing underrepresented groups on the basis of changing demographics of society and the profession,

- a shift in focus from a national perspective to a regional or local perspective on underrepresentation, and

- stimulate data collection and reporting on the broad range of racial and ethnic self-descriptions.

Before June 26, 2003, the AAMC used the term "underrepresented minority (URM)," which consisted of Blacks, Mexican-Americans, Native Americans (that is, American Indians, Alaska Natives, and Native Hawaiians), and mainland Puerto Ricans. The AAMC remains committed to ensuring access to medical education and medicinerelated careers for individuals from these four historically underrepresented racial/ethnic groups. (See https://www. aamc.org/initiatives/urm/)

The American Association of Colleges of Osteopathic Medicine defines underrepresented minorities to include Hispanic/Latino ethnicity, Black/African American, Native American/Alaska Native and Hawaiian/Pacific
Islander. (See https://www.aacom.org/become-a-doctor/ diversity/diversity-data/applicants)

\section{PROPOSED POLICY STATEMENT 1}

Following this consideration, the taskforce agreed that a more contemporary approach was needed and could be used long-term. They reviewed the policies that have been passed by the AACP House of Delegates related to diversity and inclusion and appreciated their role as educational policy, but felt it was important based on the AACP Core values to have a statement of representation. The taskforce developed a statement of representation in pharmacy and recommended that the AACP House of Delegates adopt the following for the Association:

A diverse student body, faculty, administration, and staff contribute to improvements in health equity. AACP member institutions strive to develop faculty, pharmacists and scientists whose background, perspectives, and experiences reflect the diverse communities they serve.

The policy was passed by the 2016 AACP House of Delegates as follows:

AACP recognizes that a diverse student body, faculty, administration, and staff contribute to improvements in health equity and therefore encourages member institutions to develop faculty, staff, pharmacists and scientists whose background, perspectives, and experiences reflect the diverse communities they serve.

In addition to the statement on representation in pharmacy, the taskforce is currently working on a white paper for academic pharmacy that outlines why diversity is important and what impacts our investment in human capital. The white paper will also include the barriers, game-changers and short and long-term strategies to impact climate, the people (including admissions and recruitment), and the compensation that impact academic pharmacy's human capital. 